УДК 338.0

\title{
ОЦЕНКА СТОИМОСТИ ЗОЛОТОРУДНЫХ МЕСТОРОЖДЕНИЙ С УЧЕТОМ ВЕЛИЧИНЫ КАПИТАЛЬНЫХ ЗАТРАТ
}

\section{А.Ю.ЗАЙЦЕВ}

АО «Полиметалл УК», Санкт-Петербург, Россия

\begin{abstract}
В статье рассматриваются вопросы геолого-экономической и стоимостной оценки месторождений полезных ископаемых. Существующие методики обладают рядом преимуществ и недостатков, но строятся на единых показателях оценки без учета особенностей каждого месторождения. Автором предлагается методика, позволяющая быстро и просто определить стоимость месторождения золота на основе данных рудных запасов. Предлагаемая методика позволяет определить реальную стоимость месторождения золота с учетом включения затрат на развитие и освоение месторождения, а также рассчитать предельную (рекомендуемую) величину инвестиций по сделке. Кроме того, методика дает возможность оценить вклад запасов и ресурсов минерального сырья в общую рыночную стоимость горно-добывающего предприятия.

Методика основана на анализе эмпирического материала, в качестве которого послужили факты реальных сделок покупки месторождений золота (и сопутствующих металлов) компанией Polymetal International plc. В результате статистического исследования получена формула для определения предельной стоимости месторождения с учетом включения затрат на развитие и освоение месторождения. Сопоставление реальной стоимости месторождений, определенной по результатам сделок с прогнозными значениями, показывает довольно высокую сходимость $(R=0,97)$. Основную ошибку в уравнения прогноза вносит недоучет факторов географической позиции объектов, инфраструктуры и наличия имущественного комплекса. Проверка методики на трех примерах сделок по приобретениям золотых активов компанией Polymetal International plc показала хорошую сходимость с реальной ценой сделок.
\end{abstract}

Ключевые слова: оценка месторождений; инвестиции; стоимость месторождения; оценка запасов

Как цитировать эту статью: Зайцев А.Ю. Оценка стоимости золоторудных месторождений с учетом величины капитальных затрат // Записки Горного института. 2018. Т. 233. С. 547-553. DOI:10.31897/PMI.2018.5.547

Ведение. В последнее десятилетие золоторудная промышленность является одной из наиболее привлекательных отраслей для инвестирования, что подтверждается проявлением интереса к ней со стороны достаточного количества инвесторов. С 2008 г. мировое производство золота постоянно растет, однако активное освоение золоторудных месторождений приводит к истощению легкодоступных участков недр, минерально-сырьевой базы и включению в освоение более сложных, труднодоступных месторождений. Освоение сложных месторождений приводит к росту инвестиционных затрат, потенциальные инвесторы предъявляют более высокие требования к инструментам оценок перспективности приобретения месторождения и будущего дохода. Разработка методики оценки стоимости месторождения, которая бы позволяла потенциальному инвестору корректно определить перспективность его приобретения и освоения, имеет большое значение, как в нашей стране, так и за рубежом $[11,12]$. Методика может быть полезна и для определения экономического эффекта от проведения геологоразведочных работ $[4,7]$.

Обсуждение. Основные методы оценки месторождений полезных ископаемых в мире и России: на основе доходного подхода (метод дисконтирования денежных потоков), его разновидности - модели Ольсона [2], на основе затратного и сравнительного подхода. Наиболее распространенным методом оценки стоимости приобретения месторождения является метод аукционных торгов с элементами стоимостной оценки $[1,5]$.

Существующие методы оценки стоимости приобретения месторождения имеют ряд недостатков. В них в полной мере не учитываются: сложность геологии месторождения; неопределенность технологических и технических параметров освоения; изменчивость экономических, горнотехнических условий в процессе эксплуатации месторождения. Данные факторы не дают возможности однозначно определить стоимость приобретения месторождения, что усложняет (или даже делает невозможным) принятие решения о его приобретении. Таким образом, очевидно, что на сегодняшний день нет эффективного метода геолого-экономической и стоимостной оценки месторождений полезных ископаемых. 
Качество оценки потенциала, а также возможных рисков его освоения непосредственно связано с повышением доходности месторождений. Для принятия решения о покупке месторождения самым логичным и очевидным является построение технико-экономической, а по сути математической модели месторождения. Подобная модель позволяет сопоставить характеристики месторождения с затратами на его освоение, тем самым подтвердить вероятность успешного результата. Одной из систем, позволяющей принять решение о приобретении и освоении месторождения, является скоринговая модель оценки месторождения [10]. Такая модель оценки строится на основе данных подтвержденных запасов категорий measured, indicated и inferred, proved paнеe успешно освоенных месторождений-аналогов. В результате оценки происходит разделение потенциальных месторождений на те, которые выгодно отрабатывать в текущей экономической ситуации и те, освоение которых на сегодняшний день неэффективно.

Скоринговая модель оценки месторождения значительно увеличивает скорость принятия решения инвестором о возможности его приобретения с целью дальнейшего освоения, а также наделяет его уверенностью относительно принимаемого решения. Для классификации месторождений на различные группы должны быть известны характеристики:

- местонахождение, климат, транспортная логистика;

- масштаб месторождения, величина запасов месторождения по категориям;

- технология способа добычи и переработки руд;

- предполагаемый способ отработки;

- горно-геологические и гидрогеологические условия;

• наличие перерабатывающих мощностей и логистической инфраструктуры.

Таким образом, скоринговые модели - статистические модели оценки платежеспособности предприятия, поскольку месторождение или группа месторождений составляют основу и суть горно-добывающего предприятия.

Для оценки возможности освоения месторождения производится анализ наличия подтвержденных запасов. Инвестору необходимо понимание величины готовых к отработке балансовых запасов, а также определение возможной перспективы забалансовых запасов, освоение которых в данный момент экономически нецелесообразно.

К факторам, оказывающим значительное влияние на возможность освоения и стоимость месторождения, относятся:

- условия эксплуатации - мощность рудного тела, глубина залегания с оптимальным для отработки содержанием, гидрологические особенности;

- качество минерального сырья, например, содержание ценных компонентов;

- развитость инфраструктуры в районах ведения горных работ;

- внутренние и международные цены на золото;

- горно-технические и экологические условия эксплуатации месторождения;

- технологические свойства руды (первичная, окисленная, упорная);

- расположение месторождения по отношению к транспортным магистралям, центрам переработки и использования руды или полуфабрикатов;

- период строительства горного предприятия и его мощность;

- период эксплуатации месторождения;

- наличие трудовых ресурсов;

- существующая система налогообложения, отчислений и платежей в сфере недропользования и другие.

Условно все перечисленные факторы можно разделить на три группы: горно-геологические, географические, экономические. В самом упрощенном виде скоринговая модель представляет собой взвешенную сумму определенных горно-геологических, географических, экономических характеристик. В результате получается показатель стоимости капитальных затрат месторождения.

Показатель каждого месторождения сравнивается с рассчитанным числовым порогом, который, по существу, является линией безубыточности. Его физический смысл заключается в следующем: количество потраченных средств на капитальные вложения для того, чтобы запустить месторождение в эксплуатацию, но при этом окупить первоначальные капитальные и последующие текущие затраты на его отработку. Месторождения с показателем ниже этого порога являются кандидатами к освоению. 
Методология. В сложившейся ситуации предлагается использовать методику оценки стоимости месторождения, основанную на анализе данных сделок по месторождениям, публикуемой крупными российскими золотодобывающими компаниями, и анализе инвестиций в действующие месторождения. Методика оценки формируется на основании стоимости сделок купли - продажи месторождений, затрат на геологоразведку, вложений капитального характера в строительство и приобретение техники и оборудования.

Данный подход рассматривался ранее $[3,6]$ и оценивал стоимость месторождения на основании запасов месторождения. Однако в нем отсутствует один из определяющих факторов для запуска и последующей эксплуатации месторождения - стоимость геологоразведки и капитальных вложений. С учетом растущей сложности и труднодоступности освоения новых месторождений роль этих расходов становится определяющей. Уточнение типизации руд, горногеологических условий и содержания полезного металла требуют различных принципов переработки и в значительной степени влияют на инвестиции в проект (капитальные затраты).

Включение данных затрат в оценку необходимо не только для инвестора, как потенциального покупателя, но и для государства, которое администрирует геологоразведочный процесс, а также формирует поступления в части доходов бюджета от продажи права на освоение недр и налогов от разработки месторождений.

Предложенная методика оценки позволит более корректно оценить:

• стоимость месторождений с небольшой долей запасов или низким качеством руд;

- объективную стоимость низкорентабельных месторождений, числящихся на государственном балансе запасов;

- риски разработки новых месторождений.

Объективная проведенная оценка месторождений создаст предпосылки для определения льготных, эффективных условий для привлечения инвестора.

Разработка методики оценки стоимости месторождения проводилась на основе анализа деятельности одного из активных участников сделок купли - продажи на рынке золотых и комплексных золотосодержащих месторождений стран СНГ - Polymetal International plc (табл.1). Выбор компании обусловлен следующими факторами:

- месторождения приобретались у бывших владельцев на основе рыночных сделок и в условиях конкуренции, что позволяет говорить об объективности оценок,

- информация о рентабельности эксплуатируемых месторождения с разными типами руд, в том числе, и сложной типизации (упорные и другие типы руд), в различных регионах стран СНГ (разнообразие климатических, логистических, энергетических условий);

- открытость деятельности компании (критерий рентабельности на основе финансовой отчетности позволяет выбрать месторождения для их последующего анализа).

Данные по сделкам купли-продажи и величины CAPEX* месторождений компанией Polymetal

\begin{tabular}{|c|c|c|c|c|c|}
\hline Месторождение & \multicolumn{2}{|c|}{ Запасы и ресурсы, Аu экв. т } & $\begin{array}{c}\text { Сумма сделки, } \\
\text { млн дол. }\end{array}$ & САРЕХ, млн дол. & $\begin{array}{c}\text { Стоимость приобретения } \\
\text { + САРЕХ }\end{array}$ \\
\hline \multicolumn{6}{|c|}{ Магадан } \\
\hline Кубака & $\begin{array}{l}\text { Measured } \\
\text { Indicated } \\
\text { Inferred }\end{array}$ & $\begin{array}{l}4,48 \\
3,93 \\
2,41\end{array}$ & 21,3 & 55 & 76,3 \\
\hline Биркачан & $\begin{array}{l}\text { Proved } \\
\text { Inferred }\end{array}$ & $\begin{array}{c}13,29 \\
0,00\end{array}$ & & & \\
\hline Ороч & $\begin{array}{l}\text { Measured } \\
\text { Indicated } \\
\text { Inferred }\end{array}$ & $\begin{array}{c}5,99 \\
14,92 \\
10,13\end{array}$ & & & \\
\hline Сопка Кварцевая и Дальнее & $\begin{array}{l}\text { Indicated } \\
\text { Inferred }\end{array}$ & $\begin{array}{l}31,52 \\
11,14\end{array}$ & 94 & 42 & 136 \\
\hline Ольча & Inferred & 22,43 & 13,5 & 15 & 28,5 \\
\hline
\end{tabular}

${ }^{*} \mathrm{CAPEX}$ - от англ. capital expenditure - капитальные затраты, расходы на приобретение или обновление необоротных активов 
Окончание табл.1

\begin{tabular}{|c|c|c|c|c|c|}
\hline Месторождение & \multicolumn{2}{|c|}{ Запасы и ресурсы, Аu экв. т } & $\begin{array}{l}\text { Сумма сделки, } \\
\text { млн дол. }\end{array}$ & САРЕХ, млн дол. & $\begin{array}{c}\text { Стоимость приобретения } \\
\text { + САРЕХ }\end{array}$ \\
\hline \multicolumn{6}{|c|}{ Чукотка } \\
\hline Майское & \begin{tabular}{|l} 
Proved \\
Indicated \\
Inferred
\end{tabular} & $\begin{array}{c}1,80 \\
9,98 \\
139,42\end{array}$ & 99,5 & 205 & 304,5 \\
\hline \multicolumn{6}{|c|}{ Хабаровский край } \\
\hline $\begin{array}{l}\text { Светлое } \\
\text { Албазино }\end{array}$ & $\mid \begin{array}{l}\text { Inferred } \\
\text { Proved }\end{array}$ & $\begin{array}{l}34,30 \\
44,15\end{array}$ & $\begin{array}{l}9,3 \\
7\end{array}$ & $\begin{array}{l}51 \\
58\end{array}$ & $\begin{array}{c}60,3 \\
65\end{array}$ \\
\hline \multicolumn{6}{|c|}{ Казахстан } \\
\hline Варваринское & \begin{tabular}{|l} 
Indicated \\
Inferred
\end{tabular} & $\begin{array}{c}99,23 \\
13,6\end{array}$ & 277,5 & 81 & 358,5 \\
\hline Комаровское & $\begin{array}{l}\text { Indicated } \\
\text { Inferred }\end{array}$ & $\begin{array}{c}43,5 \\
0\end{array}$ & 100 & 6 & 106 \\
\hline Бакырчик и Большевик & $\begin{array}{l}\text { Indicated } \\
\text { Inferred }\end{array}$ & $\begin{array}{c}258 \\
91\end{array}$ & 618,5 & 320 & 938,5 \\
\hline \multicolumn{6}{|c|}{ Перспективные месторождения } \\
\hline Кутын & $\begin{array}{l}\text { Measured } \\
\text { Inferred }\end{array}$ & $\begin{array}{l}11,14 \\
22,25\end{array}$ & 67 & & 67 \\
\hline Светлоборское & Inferred & 28,41 & 9,7 & & 9,7 \\
\hline Маминское & $\begin{array}{l}\text { Proved } \\
\text { Measured } \\
\text { Indicated }\end{array}$ & $\begin{array}{l}9,16 \\
1,37 \\
1,71\end{array}$ & 86,5 & 1 & 87,5 \\
\hline
\end{tabular}

Другие золотодобывающие российские компании публикуют только общие данные по сделкам, не указывая конкретную стоимость сделок по своим приобретениям, либо приобретают их непосредственно у государства, поэтому такие сделки нельзя признать рыночными, а их стоимость - объективной (справедливой).

Для проведения сравнительного анализа были отобраны месторождения, удовлетворяющие следующим условиям:

- с запасами категорий measured, indicated и inferred, proved. Запасы категории probable не учитываются, поскольку содержат высокую степень неопределенности, что увеличивает риск некорректности расчета $[13,14]$. В расчете используются запасы, подтвержденные на момент сделки;

- приобретенные в конкурентных условиях, т.е. с рыночной ценой, за исключением месторождений, прилегающих к действующим лицензионным площадям. Все месторождения, показанные в табл.1, отвечают данному условию.

Оценка стоимости золоторудных месторождений будет основана на выявлении линейной зависимости инвестиций от величины запасов на основе метода наименьших квадратов (МНК)

$$
F(a, b)=\sum_{i=1}^{n}\left(y_{i}-\left(a x_{i}+b\right)\right)^{2} .
$$

В предложенной методике результатом будет определение коэффициентов линейной зависимости, при которых функция переменных $a$ и $b$ принимает наименьшее значение.

Данные табл.1 обобщим для проведения расчетов (табл.2).

Удельный показатель инвестиций равен 2,4 млн дол./т. Показатели месторождений Кутын, Светлоборское, Маминское являются некорректными для включения в анализ из-за отсутствия величины CAPEX в расчете. С целью точной оценки зависимости путем исключения выбросов при расчете данные по этим месторождениям будут исключены из анализа.

Составим стандартную систему уравнений:

$$
\left\{\begin{array}{l}
a \sum x_{i}^{2}+b \sum x_{1}=\sum x_{i} y_{i}, \\
a \sum x_{i}+b n=\sum y_{i},
\end{array}\right.
$$

где $x$ - величина запасов, т; $y$ - величина стоимости сделки с учетом САРЕХ, млн дол.

Система будет выглядеть следующим образом:

$$
\left\{\begin{array}{l}
167775 a+855 b=434224 \\
855 a+9 b=2074
\end{array}\right.
$$


Оценка стоимости золоторудных месторождений...

Удельный показатель инвестиций на тонну запасов месторождений компании Polymetal

\begin{tabular}{l|c|c|c|c}
\hline \multicolumn{1}{c|}{ Месторождения } & Запасы, т & $\begin{array}{c}\text { Величина сделки +САРЕХ, } \\
\text { млн дол. }\end{array}$ & $\begin{array}{c}\text { (Сделка +САРЕХ)/запас, } \\
\text { млн дол./т }\end{array}$ & $\begin{array}{c}\text { Отклонение от удельного } \\
\text { показателя, \% }\end{array}$ \\
\hline Кубака & 55,15 & 76,3 & 1,4 & $-42,5$ \\
Ольча & 22,43 & 28,5 & 1,3 & $-45,8$ \\
Майское & 151,20 & 304,5 & 2,0 & $-16,7$ \\
Светлое & 34,30 & 60,3 & 1,8 & $-25,0$ \\
Албазино & 44,15 & 65,0 & 1,5 & $-37,5$ \\
Кутын & 33,39 & 67,0 & 2,0 & $-16,7$ \\
Сопка Кварцевая & 42,66 & 136,0 & 3,2 & $+33,3$ \\
Комаровское & 43,50 & 106,0 & 2,4 & 0 \\
Варваринское & 112,83 & 358,5 & 3,2 & $+33,3$ \\
Кызыл & 349,00 & 938,5 & 2,7 & $+12,5$ \\
Светлоборское & 28,41 & 9,7 & 0,3 & $-87,5$ \\
Маминское & 12,24 & 87,5 & 7,1 & $+195,8$ \\
Среднее & 929,26 & 2237,8 & 2,4 & -
\end{tabular}

Решаем систему методом Крамера:

$$
\begin{gathered}
\Delta a=\left|\begin{array}{rr}
434224 & 855 \\
2074 & 9
\end{array}\right|=2134642 ; \\
\Delta b=\left|\begin{array}{rr}
167775 & 434224 \\
855 & 2074
\end{array}\right|=-23456831 .
\end{gathered}
$$

По итогам вычислений коэффициенты аппроксимирующей функции равны:

$$
y=a x+b, \text { где } a=2,74, b=-30,13 .
$$

Графический вариант зависимости представлен на рис.1.

Величины инвестиций (табл.2) и запасов показывают довольно высокую сходимость (рис.1) $R^{2}=0,97$. В результате предложенная модель оценки представляет собой разновидность сравнительного подхода и удобный инструмент для расчета стоимости сделки с учетом будущих инвестиций.

В явном виде формула для определения оптимального размера инвестиций с учетом САРЕХ имеет вид:

$$
y_{\mathrm{CAPEX}}=(2,74 x+30,13)-\mathrm{M}_{100},
$$

где $\mathrm{M}_{100}$ - полная (100 \%) стоимость приобретения месторождения, млн. дол.

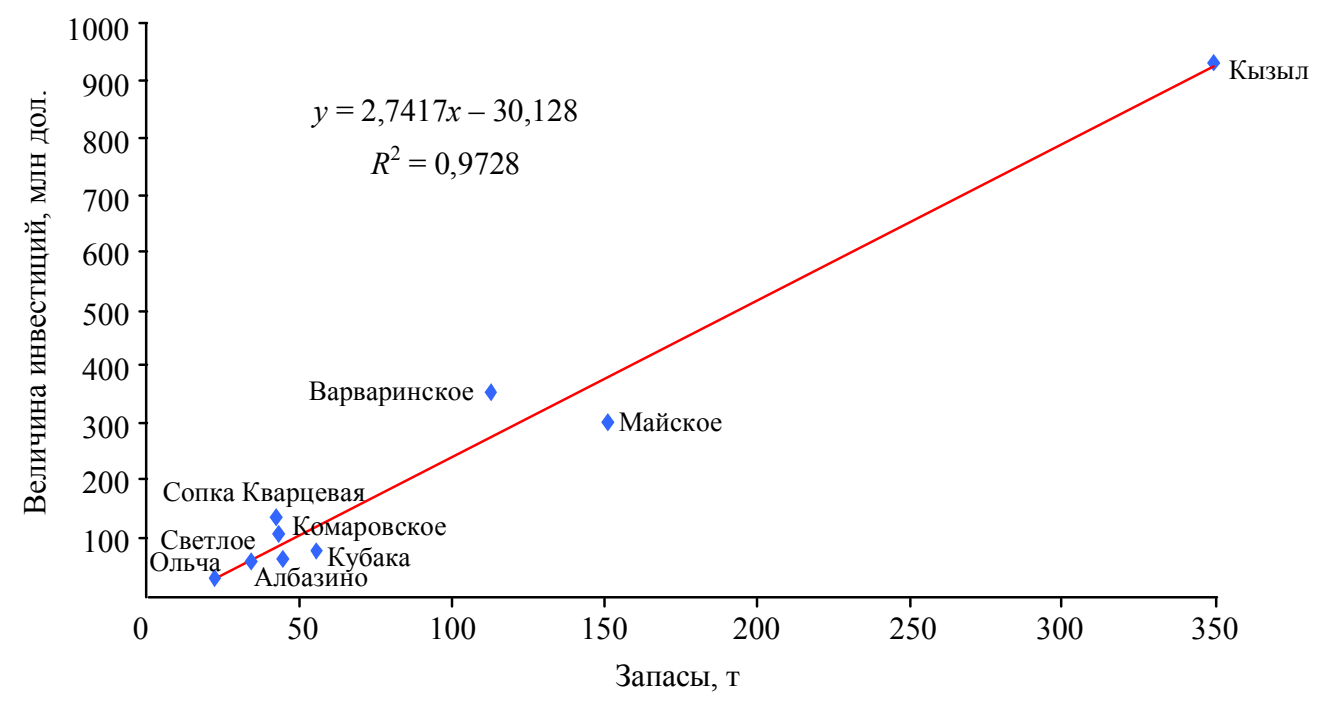

Рис.1. График зависимости размера инвестиций с учетом САРЕХ от запасов месторождения 
Оценка стоимости золоторудных месторождений...

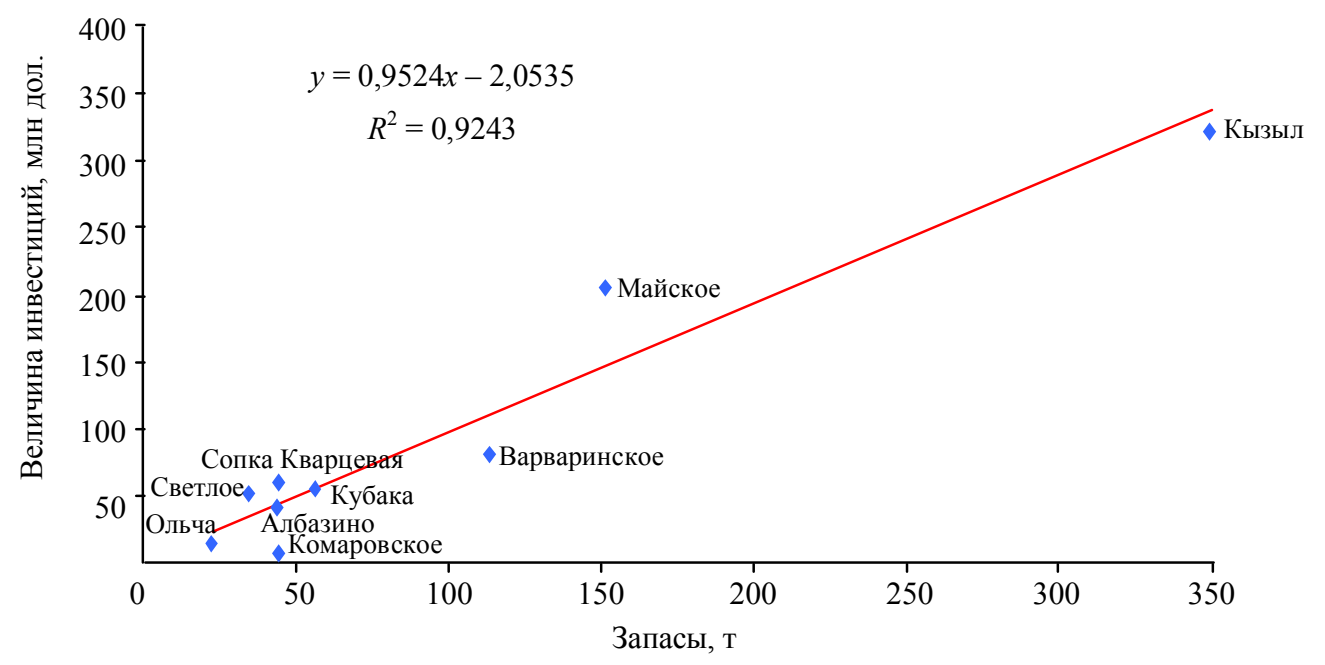

Рис.2. График зависимости величины САРЕХ от запасов месторождения

Величина САРЕХ является предельной для инвестора, в случае если прогнозное значение CAPEX выше оптимальной расчетной величины, то сделка по своим параметрам хуже среднерыночной, и инвестиции будут экономически неоправданными.

На основе полученной расчетной формулы были определены предельные величины САРЕХ для месторождений, не включенных в анализ, а также рассматриваемых как проектные (перспективные) для компании Polymetal.

Предельная величина САРЕХ для месторождений, не попавших в анализ, составит, млн дол.: Светлоборское 38,1, Кутын - 5,6, Маминское - 83,1. Как видно из полученных результатов, величины САРЕХ для месторождений Кутын и Маминское являются отрицательными, что говорит о завышенной цене их приобретения.

Перспективный проект - месторождение Нежданинское, в котором Polymetal приобрел долю 15,3 \% за 18 млн дол. при ориентировочной стоимости приобретения 100 \%-ной доли за 120 млн дол., с запасами золота категорий measured, indicated, inferred, proved в объеме 230 т, предельная величина САРЕХ составит 480,5 млн дол.

Данный подход применим в случае, когда известна стоимость приобретения месторождения. Но что делать в случае, если стоимость приобретения неизвестна, либо наоборот, покупатель обладает ограниченными финансовыми ресурсами и хочет добиться определенной для себя стоимости месторождения? Можно использовать тот же подход, но в качестве зависимых величин использовать стоимость сделки и величину капитальных вложений. В данном случае наблюдается весьма высокая сходимость (рис.2) $R^{2}=0,9243$.

В явном виде формула для определения оптимального размера САРЕХ имеет вид:

$$
y_{\text {CAPEX }}=0,9524 x+2,0535 .
$$

Таким образом, определив в соответствии с формулой (5) предельную стоимость инвестиций и отняв от полученного результата стоимость САРЕХ из формулы (4), получим предельную стоимость месторождения.

Учитывая принципы оценки и возможность добавления новых данных, можно отметить, что рассмотренная методика позволяет корректно и эффективно оценить стоимость месторождения, а также благодаря своей гибкости с возможностью включения информации по новым сделкам дать более точную оценку для расчетов и рекомендаций по приобретению месторождений.

Заключение. Предлагаемая методика является начальным шагом для эффективной оценки золоторудных месторождений с учетом растущей сложности и труднодоступности освоения. Однако требуется создание единой базы по инвестициям, проведенным сделкам и капитальным вложениям, что позволит инвесторам более точно определять стоимость сделки, будущих капитальных вложений, значительно снижать финансовый риск, а государству эффективно реализовывать проекты по освоению минерально-сырьевой базы и формировать эффективную цену для реализации недропользователю. Все это в комплексе позволит быстрее осваивать и запускать месторождения в эксплуатацию. 
Оценка стоимости золоторудных месторождений...

Предложенная методика позволит оценить предельную стоимость проекта, а также возможность влиять на переговорный процесс в ходе сделки купли-продажи и корректно определить потенциальному инвестору перспективность приобретения месторождения и получаемого будущего дохода.

Методика оценки имеет перспективу на дальнейшее совершенствование и развитие, поскольку сейчас востребован простой, прозрачный и доступный метод определения как стоимостной оценки месторождения, основанной на величине его запасов, так и ожидаемой величины инвестиций в его разработку.

\section{ЛИТЕРАТУРА}

1. Ампилов Ю.П. Экономическая геология / Ю.П.Ампилов, А.А.Герт. М.: Геоинформмарк, 2006. 344 с.

2. Косовцева T.P. Управление ценностью горной компании при реализации стратегических инвестиционных проектов / Т.Р.Косовцева, Т.В.Пономаренко // Записки Горного института. 2014. Т. 208. С. 124-131.

3. Котляров И.Д. Методика учета рисков при геолого-экономической и стоимостной оценке месторождений / И.Д.Котляров, С.В.Петров // Горный журнал. 2014. № 9. С. 94-99.

4. Котляров И.Д. Оценка экономического эффекта от использования аутсорсинга в нефтегазовой отрасли // Проблемы экономики и управления нефтегазовым комплексом. 2014. № 3. С. 20-23.

5. Подтуркин Ю.А. Проблемы стоимостной оценки месторождений полезных ископаемых / Ю.А.Подтуркин, В.А.Коткин // Минеральные ресурсы России. Экономика и управление. 2004. № 4. С. 30-33.

6. Прогнозирование цены золота в недрах / С.В.Петров, И.Д.Котляров, А.Б.Кацнельсон, М.С.Сень // Обогащение руд. 2016. № 2. C. 3-8.

7. Сень М.С. Оценка добавленной стоимости минерального актива в результате проведения геологоразведочных работ // Недропользование XXI век. 2013. № 3. С. 45.

8. Шаклеин С.В. Использование отечественного и зарубежного опыта при разработке новой российской «Классификации запасов и прогнозных ресурсов твердых полезных ископаемых» // Недропользование ХХІ век. 2014. № 6. С. 64-68.

9. Эпштейн И.В. Концепция новой классификации запасов ТПИ с позиций недропользователя, привлекающего инвестиции через биржи // Недропользование XXI век. 2015. № 2. С. 74-91.

10. Anderson R. The Credit Scoring Toolkit: Theory and Practice for Retail Credit Risk Management and Decision Automation. Oxford: Oxford University Press. 2007. 108 p.

11. Kreuzer O.P. Risk and Uncertainty in Mineral Exploration: Implications For Valuing Mineral Exploration Properties / O.P.Kreuzer, M.A.Etheridge // AIG News. 2010. № 100. P. 20-28.

12. Satuga P. Simple and Advanced Methods of Mineral Projects Risk Analysis - Application Examples / P.Saługa, E.J.Sobczyk // Underground Mining: New Technologies, Safety and Sustainable Development, Proceedings of the 6th International Mining Forum 2005, Cracow - Szczyrk - Wieliczka, Poland, 23-27 February 2005. Taylor \& Francis, 2005. P. 137-152.

Автор А.Ю.Зайщев, руководитель проектов, azaitsev72@таil.ru (АО «Полиметалл УК», Санкт-Петербург, Россия). Статья поступила в редакциию 18.03.2018.

Статья принята к публикачии 10.07.2018. 